\title{
A IDENTIDADE EVANGÉLICA EM DISPUTA ${ }^{1}$
}

\section{Maria das Dores Campos Machado}

Resumo: O objetivo do presente texto é comentar o instigante artigo "Irmãos contra o Império: evangélicos de esquerda nas eleições 2020 no Brasil", escrito pela antropóloga Christina Vital da Cunha e publicado neste volume da Debates do NER. Assim, discute-se a perspectiva teórica adotada pela autora para analisar a) o surgimento de novos atores coletivos e individuais, b) os embates no interior do campo cristáo em torno da identidade religiosa e da política de representação adotada nos últimos anos por algumas denominaçóes, assim como c) as linhas de continuidades e descontinuidades na atuação pública dos evangélicos na sociedade brasileira.

Palavras-chave: Identidade; Religião; Evangélicos; Brasil.

THE EVANGELICAL IDENTITY IN DISPUTE

Abstract: The objective of this text is to comment on the instigating article "Brothers against the Empire: left wing evangelicals in the 2020 elections in Brazil", written by anthropologist Christina Vital da Cunha and published in this volume of Debates do NER.Thus, we discuss the theoretical perspective adopted by the author to analyze a) the emergence of new collective and individual actors, b) the conflicts within the Christian field around religious identity and the representation policy adopted in recent years by some denominations, as well as c) the lines of continuities and discontinuities in the public performance of evangelicals in Brazilian society.

Keywords: Identity; Religion; Evangelicals; Brazil.

${ }^{1}$ Como citar: MACHADO, Maria das Dores Campos. A identidade evangélica em disputa. Debates do NER, Porto Alegre, ano 21, n. 39, p. 83-89, 2021.

${ }^{2}$ Professora voluntária do Programa de Pós-Graduação em Serviço Social da Universidade Federal do Rio de Janeiro, Brasil. E-mail: mddcm@uol.com.br. ORCID: https://orcid. org/0000-0002-6724-4013. 
O artigo de Christina Vital apresenta dados muito interessantes sobre as controvérsias em torno da identidade evangélica durante o pleito eleitoral de 2020. Revisitando a produção acadêmica sobre a participação de atores religiosos nos processos eleitorais anteriores, a autora reforça as teses sobre a heterogeneidade e os conflitos de interesses entre os segmentos genericamente classificados como evangélicos no Brasil. Também sugere transformaçóes nos discursos, nas agendas políticas e nas estratégias eleitorais das candidaturas que apresentavam vínculos identitários com este braço do cristianismo. O termo identidade é reiteradamente mobilizado pelos entrevistados da pesquisa, que serviu de base para o artigo, indicando que as disputas pela representação política dos evangélicos passa pelo embate em torno da própria identidade evangélica. A autora, entretanto, preferiu adotar outro enquadramento teórico e eleger a categoria de performances para explicar os discursos e as estratégias de ação dos atores coletivos e individuais de seu estudo. Penso que, nos estudos culturais que tratam do processo de construção das identidades coletivas (Hall, 2000; Gupta e Ferguson, 2000; Bhabha, 1998; Agier, 2001; Brah, 2006), poder-se-ia encontrar pistas fecundas não só para articular a questão identitária com a performatividade dos atores, mas também para se explicar as transmutaçôes no campo religioso brasileiro ocorridas nas últimas décadas.

Avtar Brah (2006, p.371-372) define a identidade coletiva como um "processo de significação pelo qual experiências comuns em torno de eixos específicos de diferenciação - classe, castas ou religião - são investidas de significados particulares”. Nessa perspectiva teórica, a construção de uma determinada identidade coletiva implica no apagamento parcial da memória da heterogeneidade interna, o que não significa a eliminação das diferenças e das relaçóes de poder na coletividade em questáo. Ou seja, o caráter parcial da "supressão do sentido de uma identidade pela asserção de outra" acaba por possibilitar a coexistência de diferentes identidades ou releituras das identidades coletivas frente às mudanças nos contextos econômicos, socioculturais e políticos. 
Interessa-me destacar, nesta discussão de Avtar Brah, não só a dimensão contingencial e processual das identidades coletivas, mas também a ideia de que "matrizes de significados" e memórias históricas que foram suprimidas em determinadas sociedades e contextos possam tornar-se salientes ou conseguir circular com mais visibilidade em outros contextos sociais e temporalidades. Creio que esta seria uma boa chave interpretativa para as controvérsias apresentadas por Christina Vital em torno das eleiçôes de 2020 e, mais especificamente, de quem poderia representar politicamente os evangélicos na sociedade brasileira contemporânea. Os segmentos religiosos que criaram e/ou integraram o movimento da Bancada Evangélica Popular (BEP) e Cristãos contra o Fascismo, com vistas às disputas eleitorais daquele ano, parecem mobilizar discursos e matrizes de significados distintos daqueles que se tornaram hegemônicos na segunda década do século XXI no meio evangélico brasileiro.

A associação da redemocratização brasileira com o surgimento dos movimentos identitários que adotaram a política de reconhecimento já foi exaustivamente explorada pelas ciências sociais e políticas, dispensando-nos de maiores comentários. Na esfera religiosa, Joanildo Burity (2016) mostrou-nos como o processo de minoritização dos evangélicos estava associado a uma diferenciação e busca de equiparação de setores pentecostais, protestantes históricos e neopentecostais em relação aos católicos e à Igreja Católica. Sugeriu também que fatores socioeconômicos e políticos fizeram com que o discurso da minoria que queria tratamento equânime fosse substituído, depois do impeachment de Dilma Rousseff, em 2016, pela configuração discursiva da maioria cristá. De modo que o deslocamento de setores evangélicos da base de apoio do governo petista para a oposição e mais radicalmente para a direita exigiu uma reconfiguração do discurso político desses atores religiosos na esfera pública.

Os dados apresentados por Christina Vital indicam que neste duplo deslizamento - prático e discursivo - a disputa sobre quem define a identidade evangélica, quem pode mobilizá-la politicamente e quem efetivamente representa os evangélicos na arena política tornou-se mais perceptível. Só 
que distintamente dos anos 80/90 e 2000, em que a alteridade central era entre evangélicos e católicos, no ano de 2020 formas alternativas de diferenciação e identificação - como a do Movimento Evangélico Progressista (MEP) - vão ser revisitadas para a produçáo de contradiscursos articulando setores evangélicos com os movimentos de esquerda e/ou com pautas mais liberalizantes nos campos das relaçóes raciais e de gênero, bem como da sexualidade.

O MEP faz parte da memória histórica de segmentos classificados como evangélicos e alguns dos seus integrantes circulam nos cursos de formação política e nos debates teológicos e acadêmicos contemporâneos. De modo que é possível que os integrantes dos movimentos Cristão contra o Fascismo e da Bancada Evangélica Popular tenham realizado uma releitura da identidade evangélica a partir dos significados preconizados pelo MEP e pela Teologia da Libertação, que também mobilizou setores cristãos - católicos e evangélicos - nos anos 60,70 e 80.

Alteraram-se as circunstâncias econômicas, multiplicou-se o número de fiéis evangélicos na sociedade, a política de representaçáo fortaleceu politicamente segmentos da Assembleia de Deus, da Universal e dos Batistas que também foram buscar na memória histórica discursos e práticas associadas aos cristáos no apoio aos militares nos anos 60 e 70 . A ênfase na família e na moralidade já estava em discursos de alguns pastores como do batista Nilson Fanini (Cowan, 2014) e isto também precisaria ser destacado no texto, pois as revisôes das configuraçôes discursivas são dos dois lados - evangélicos de direita e de esquerda. Afinal, a mesma Universal que, em 2020, usou a Folha Universal para desqualificar os partidos ditos de esquerda, nas eleiçóes majoritárias de 2002 havia empregado expediente semelhante, no sentido inverso, para desconstruir a representaçáo demoníaca do representante do Partido dos Trabalhadores entre os evangélicos. Ou seja, no pleito de 2002, Lula representava a possibilidade de redefinição do estatuto político dos evangélicos, em 2020, Jair Bolsonaro acenou com a possibilidade de redefinição ideológica na sociedade e com o alargamento das benesses políticas 
para as mega igrejas evangélicas. A luta que era por representação política tornou-se uma disputa pela hegemonia cultural na sociedade brasileira.

É importante registrar também que os movimentos feministas e pela diversidade sexual introduziram novos discursos da diferença na sociedade brasileira e que essas formas de diferenciação - baseadas no gênero e na orientação sexual - provocaram impactos na esfera religiosa (Biroli, Machado e Vaggione, 2020). Enquanto os cristãos neoconservadores - evangélicos e católicos - seguiram uma tendência global de empreender uma cruzada contra as agendas de gênero e da diversidade sexual, a nova geração dos movimentos identitários negros, feministas e LGBTT + fortaleceram as articulaçôes políticas e estabeleceram formas alternativas de organização e intervenção na esfera pública, como as Evangélicas pela Igualdade de Gênero ou a Rede de Mulheres Negras Evangélicas.

Deve-se destacar que, se o discurso neoconservador que ajudou eleger Jair Bolsonaro em 2018 foi marcado, entre outras coisas, pela rejeição das diferenças de gênero e de orientação sexual, a análise de Christina Vital sobre a disputa de 2020 nos indica que as candidaturas evangélicas de esquerda procuraram articular estes eixos de diferenciação com os já existentes no período do MEP. Dito de outra maneira, enquanto os cristãos neoconservadores concebem as diferenças como mecanismos de práticas discriminatórias, as candidaturas evangélicas de esquerda, que destacaram as dimensóes raciais, de gênero e de orientação sexual no pleito eleitoral de 2020, parecem usar a diferença para afirmar a diversidade cultural.

Não podemos deixar de levantar a hipótese de que o giro ideológico na máquina do Estado e a escolha de uma ativista evangélica conservadora para assumir o Ministério da Mulher, da Família e dos Direitos Humanos pelo presidente Bolsonaro, em 2019, tenham também sido fatores importantes nas performances realizadas pelos atores/atrizes evangélicos/as nas eleições de 2020. A entrevistada Simony dos Anjos representa uma geração de mulheres evangélicas negras que não se identifica com a representação de gênero, o discurso de intolerância e as performances de Damares Alves à frente da pasta responsável pelos direitos humanos. O lançamento de seu nome, pelo 
PSOL, para um cargo olítico majoritário no interior paulista, de certa forma reforçou o papel das mulheres na disputa atual pela enunciação identitária e ofereceu um modelo de ativismo feminino evangélico contrastante com o adotado por Damares Silva.

As diferenças de estratégias dos movimentos da esquerda evangélica contemporânea também foram destacadas no texto de Christina Vital sugerindo o caráter político do movimento Cristãos contra o Fascismo desde "o seu nascedouro" em 2018. Aqui parece ocorrer uma redução da concepçáo de política, como se ela só existisse no momento das eleiçóes, pois o movimento Frente Evangélica pelo Estado de Direito surgiu no contexto do impeachment de Dilma Rousseff tinha, e ainda tem, um caráter político. Não político eleitoral, mas era e ainda é inegavelmente político. As iniciativas de realizar cursos de formaçáo de novas lideranças e de estimular candidaturas para construir uma Bancada Evangélica Popular, ainda que náo tenham conseguido sucesso eleitoral no pleito de 2020, parecem ter sido deixadas de lado com a afirmação de que o movimento Cristáos contra o Fascismo se diferenciaria pelo caráter político. A declaração de Ariovaldo Ramos, que dá origem ao título do artigo, mostra isso.

"Quando a gente começou a Frente, lá em 2016, uma coisa ficou clara: náo tínhamos tomado uma posição só contra o golpe de Estado, mas também contra a tentativa de hegemonia da bancada Evangélica [no Congresso Nacional], principalmente, a tentativa de desenhar um perfil único 'pros' evangélicos."

Ou seja, a disputa pela identidade evangélica pode ter se tornado mais visível no pleito de 2020, mas ela já mobilizava setores cristáos à esquerda na ocasiáo da deposição de Dilma Rousseff.

\section{REFERÊNCIAS}

AGIER, Michel. Distúrbios identitários em tempos de globalização. Revista Mana 7(2), p.7-33, 2001. 
BHABHA, Homi K. O local da cultura. Belo Horizonte: Ed. da UFMG, 1998. BIROLI, Flávia; MACHADO, Maria das Dores C.; VAGGIONE, Juan. M. Gênero, Neoconservadorismo e Democracia. São Paulo: Boitempo Editorial, 2020.

BRAH, Avtar. Diferença, diversidade, diferenciação. Cadernos Pagu (26) janeiro-junho de 2006, p. 329-376, 2006.

BURITY, Joanildo. Minoritization and Pluralization: What Is the 'People' That Pentecostal Politicization Is Building? Latin American Perspectives, v. 43, p. 116-132, 2016.

COWAN, Benjamin Arthur. "Nosso Terreno" crise moral, política evangélica e a formação da "Nova Direita" brasileira. Varia hist., Belo Horizonte, v. 30, n. 52, p. 101-125, 2014.

HALL, Stuart, $A$ identidade cultural na pós-modernidade. Trad. Tomaz Tadeu da Silva, Guaracira Lopes Louro. Rio de Janeiro: DP\&A, 2000.

GUPTA, Akil; FERGUSON, James. Mais além da cultura: espaço, identidade e política da diferença. In: ARANTES, Antonio. (org.) Espaço da Diferença. São Paulo: Editora Unicamp, p.31-49, 2000 [1992].

Recebido em: 26/03/2021

Aprovado em: 26/03/2021 
